\title{
Sea water ageing of composites for ocean energy conversion systems: Influence of glass fibre type on static behaviour
}

\author{
Boisseau Amélie ${ }^{a}$, Davies Peter ${ }^{a}$,, Thiebaud Frédéric ${ }^{b, c}$ \\ a IFREMER Centre de Brest, Materials and Structures group, F-29280 Plouzané, France \\ ${ }^{\mathrm{b}}$ Université de Franche-Comté, DMA/FEMTO-ST, F-25000, Besançon, France \\ ${ }^{c}$ MAHYTEC, F-39100, Dole, France \\ *: Corresponding author : Peter Davies, email address : peter.davies@ifremer.fr
}

\begin{abstract}
:
Composite material components will be an essential part of ocean energy recovery devices, and their long term durability in sea water must be guaranteed. Despite extensive experience for boat structures and wind turbines few data exist to design structures subjected to a combination of mechanical loads and sea water immersion. This paper presents the first results from an experimental study, performed jointly with fibre manufacturers, and a resin supplier, to fill this gap. The experimental study is completed by numerical modelling to simulate the coupling between water absorption and mechanical behaviour. Sea water ageing is shown to result in a drop in quasi static mechanical properties and a change in flexural mode from compression to tension at longer ageing times, which is consistent with results from the numerical simulations.
\end{abstract}

Keywords: Composite material ; sea water ageing ; failure mechanism ; flexure ; tidal turbine 


\section{Introduction}

Ocean energy is one of the most promising renewable energy resources, and it can be broadly split into five groups [1-3]: tides, waves, tidal currents, temperature gradients and salinity gradients. Several recent evaluations of these resources suggest that their potential is of the same order as that of the present capacity of electricity generation worldwide [3]. Interest in ocean energy is not new, tidal barrage plants have been operating for many years such as the installation on the Rance estuary, in Brittany, which has been producing electricity since 1966 [4]. What is new is the level of current development and investment, several demonstration projects in the 0.5 to $1.5 \mathrm{MW}$ range are either being evaluated or will shortly be deployed, particularly wave and tidal current systems. Many devices have been proposed for wave and tidal energy conversion [1-3] but one feature of all the systems is that long term durability is essential [5]. Maintenance free-operation is a prerequisite if these systems are to be economically viable. This, together with light weight is one of the main reasons for considering composites rather than metallic structures for these applications. Fortunately there is extensive experience of composites in marine structures and in the next section a brief overview of this experience will be presented. Many studies of composites in water are also available and these will be briefly reviewed.

\subsection{Composite marine structures}

Glass fibre reinforced polymers have been the preferred material choice for small boat-builders for over 50 years [6,7]. Other marine applications include high speed ferries and a recent overview [8] provides examples of the composites used in marine vessels. Military naval applications have used large quantities of glass reinforced composites since MCMV (Mine Counter-Measure Vessel) programmes started in the 1960's. Smith has given a detailed overview of the different concepts developed by different navies [9] and some information on other large composite military structures is also available $[10,11]$.

Ship propellers are similar in many ways to tidal current turbines. While bronze is the traditional choice, composite propellers are commercially available for small boats. The offshore industry has also become interested in composite materials in recent years, and several projects have generated both material data (e.g. the Marintech programmes [12]) and prototype experience on structures such as risers [13].

\subsection{Composites in water}

In parallel with applications in service there have been many laboratory studies of the influence of moisture on composite properties. Early studies focussed on relative humidity and large amounts of data were published [14]. As part of a development of the use of composites for power station cooling water tubes a large number of durability studies were performed by EDF, in collaboration with various research institutes $[15,16]$. These studies generated data on filament wound glass reinforced epoxy composite properties after immersion in water at different temperatures for periods over 10 years. Mechanical properties of aged samples were evaluated periodically and a loss in properties was noted after 2.5 years in water at $60^{\circ} \mathrm{C}$. This was attributed to hydrolysis of the epoxy resin, and underlines the importance of resin selection; the anhydride hardener initially selected was not stable over long periods at $60^{\circ} \mathrm{C}$. Selection of an alternative hardener solved the problem, though it should be noted that at $20^{\circ} \mathrm{C}$, even after 10 years' immersion, the mechanical properties of the original (anhydride) material were still intact. More recently various authors have examined the influence of sea water on composite properties, e.g. [17-20]. Many other 
studies have focussed on the long term behaviour of composites in water, and a recent book provides an overview [21].

\subsection{Use of composites in prototype ocean energy structures}

First it should be noted that the amount of published information available from prototype tests is quite limited, as these are generally commercial developments. Concerning tidal turbines, the Seaflow project, a $300 \mathrm{~kW}$ prototype two-blade horizontal axis tidal turbine immersed off the Devon cost in June 2003 [22], used an 11 meter diameter turbine with composite blades. The construction involved a central $65 \mathrm{~mm}$ thick carbon composite spar covered by stiffened glass/epoxy fairings [23]. Also in 2003 a $300 \mathrm{~kW}$ Norwegian tidal power station was installed near Hammerfest, using three glass fibre composite blades. In 2008 within the SeaGen project a 1.2 MW twin turbine was immersed [24], using a similar design to Seaflow again by Marine Current Turbines. The blades were longer than those tested in the Seaflow project, each 7.5 meters long. By February 2010 over 350 MWh of power had been delivered into the grid. In the USA, in the RITE project, following development trials with a 3 meter diameter turbine, six turbines were installed in 2007 in New York. These used 4.9 meter diameter turbines each with three composite blades similar to existing wind turbine designs. Some blade failures were noted and the blades had to be redesigned. Other composite tidal turbine blades have been used in the OpenHydro project and it was recently reported that blade failures had occurred during trials [25].

In addition to the turbines with horizontal axes, turbines with a vertical axis have been developed, such as the Harvest prototype $[26,27]$. The different system designs result in very different loadings. For example, a turbine with an horizontal axis will be subjected to high static loads but is moderately solicited in fatigue. For a turbine with a vertical axis, each blade will see a complete load inversion during each cycle resulting in much more severe fatigue loading [27]. In addition to turbine blades, composites are also of interest for shrouds, mounting frames and other components of these systems as they can reduce weight, resulting in easier installation. Composites are also of interest for wave energy devices [28].

All these examples show that composites will be a critical part of ocean energy devices, and a thorough understanding of their long term behaviour in sea water is essential. This paper presents the static mechanical properties measured during a three year project to investigate the influence of glass fibre type on the durability of composites for marine energy applications. Fatigue test results for the same materials in air and in sea water will be presented in a subsequent paper.

\section{Materials and methods}

In order to quantify the influence of the glass fibre type as a function of the environment three infused composites have been studied, by performing static tests both in air and in natural circulating sea water, on specimens in their initial state and at different stages of ageing. The same epoxy resin has been reinforced with three different types of glass fibres. Both the resin and the fibres are currently used in wind turbine blades.

The epoxy resin is the low viscosity infusion resin MGS@ RIM 135 from Hexion ${ }^{\mathrm{TM}}$ with amine hardener RIMH 137. The reference fibre material is $17 \mu \mathrm{m}$ diameter E-glass with P196 sizing from OCV Reinforcements. Two other grades of glass fibre were also studied, Advantex® glass $(20 \mu \mathrm{m})$, and a high performance glass, the HiPer-tex ${ }^{\mathrm{TM}}$ glass $(17 \mu \mathrm{m})$, from $3 \mathrm{~B}$ and OCV. The nominal fibre properties are given in Table 1 . The reinforcement type is a quasi-unidirectional fabric reference CDM 1250 with approximately $90 \%$ unidirectional fibres 
and $10 \%$ mat and $90^{\circ}$ fibres (1 $150 \mathrm{~g} / \mathrm{m}^{2}$ warp, $50 \mathrm{~g} / \mathrm{m}^{2}$ weft and $50 \mathrm{~g} / \mathrm{m}^{2}$ chopped mat). Polyester stitching (approximately $15 \mathrm{~g} / \mathrm{m}^{2}$ ) is used to hold the fibres together. Fibre sizings were optimised for the epoxy resin.

All specimens (resin and composite) were made by infusion because it is the main process currently used to produce large wind turbine blades. They were nominally $5 \mathrm{~mm}$ thick and the composites were composed of 6 plies distributed symmetrically with respect to the mid-plane. The infusion was performed at $35^{\circ} \mathrm{C}$ in a controlled environment chamber. After infusion the composite plates, of dimensions $600 \mathrm{~mm}$ by $600 \mathrm{~mm}$, were left for 12 hours at $35^{\circ} \mathrm{C}$ in the mould, then de-moulded and post-cured for 10 hours at $70^{\circ} \mathrm{C}$.

\subsection{Quality control}

All composite panels were checked using DSC (Differential Scanning Calorimetry) to verify cure, burn-off tests to measure fibre content and interlaminar shear strength (ILSS) measurements. Table 2 shows the results. Based on experience with poorly impregnated panels an arbitrary minimum acceptable ILSS value of $45 \mathrm{MPa}$ was applied.

\subsection{Natural sea water ageing and gravimetric analysis}

Natural sea water ageing was performed on each material at different temperatures. Water absorption of a composite specimen is a function of the water absorption of the matrix and the fibre/matrix interfaces. It is generally assumed that glass fibres do not absorb water, so, in order to have a detailed understanding of the mechanisms of diffusion in a composite material, it is important to understand the kinetics of diffusion in the matrix. For this reason the natural sea water ageing was also performed on pure resin specimens infused using the same process parameters and cure cycle. Twenty four specimens $\left(50 \times 50 \times 5 \mathrm{~mm}^{3}\right)$ of each material were cut from the infused resin and composite plates, measured and weighed then distributed randomly between four natural circulating sea water tanks at different temperatures : $4^{\circ} \mathrm{C}, 20^{\circ} \mathrm{C}, 40^{\circ} \mathrm{C}$ and $60^{\circ} \mathrm{C}$. From weight measurements made throughout the ageing process the water content was determined and expressed as a percentage of the initial weights of the specimens.

\subsection{Mechanical tests}

The resin properties were measured by tensile tests on dog-bone specimens (ASTM D638 Type 1, $5 \mathrm{~mm}$ thick, two specimens per condition) at a crosshead displacement rate of $2 \mathrm{~mm} / \mathrm{min}$. A digital camera was used to measure central section strain, from the movements of two targets bonded to the specimen and an image analysis programme developed inhouse.

The mechanical properties of the three infused composite materials were also determined on dog-bone specimens, three per condition. The main test programme was based on four-point flexural tests, but some tensile and compression tests were also performed. These specimens were non-standard, $140 \mathrm{~mm}$ long, $25 \mathrm{~mm}$ wide at the ends and $10 \mathrm{~mm}$ in the centre, and $5 \mathrm{~mm}$ thick, Figure 1. For flexural tests the inner loading span was $60 \mathrm{~mm}$ and the outer span $120 \mathrm{~mm}$, loading point and support diameters were $10 \mathrm{~mm}$. The choice of a composite dog-bone specimen was dictated by preliminary results under both quasi-static and cyclic loading. When $25 \mathrm{~mm}$ wide parallel sided specimens were tested the failure mechanism for both was local indentation. The loading points, whatever their radius, caused local damage of the upper face of the specimen and initiated premature failure. Different dog-bone specimen configurations were therefore examined, and the one shown on Figure 1 
was chosen. The loading points are within the parallel sections, allowing the load introduction to be spread over a larger area and, for the materials studied here, resulted in static and fatigue failures in the central section without crushing. The specimens were loaded under displacement control at $5 \mathrm{~mm} / \mathrm{min}$ until complete failure.

Both resin and composite specimens were cut from the infused plates using a high pressure water jet. This provides an excellent surface finish without heating and gives very reproducible specimen dimensions. Figure 2 shows the flexural results from a test with strain gages on both faces, together with results from tension and compression specimens. While the initial moduli are similar for all three tests the flexural loading results in significantly higher strengths.

\section{Results}

\subsection{Diffusion kinetics}

Resin samples have been immersed in sea water for almost 700 days and the weight gains have been measured periodically. When the weight gain is plotted versus the root square of immersion time, the diffusion in the pure resin follows Fick's law. As a consequence, by using a Matlab@ routine based on the least squares method, the diffusion characteristics, in our case the diffusion coefficient $D$, can be determined according to the analytical formulation of Fick's law and the experimental data (based on the dimensions of the specimens and the mass at saturation, taken as $2.5 \%$ ). Table 3 summarizes the results.

The infused composite materials were also measured and weighed, the weight gains have been plotted versus the root square of immersion time at $4{ }^{\circ} \mathrm{C}, 20^{\circ} \mathrm{C}, 40^{\circ} \mathrm{C}$ and $60^{\circ} \mathrm{C}$. The infused E-glass composites have been immersed for almost 600 days, Figure $3 \mathrm{a}$, and the infused HP for 300 days, Figure 3b. The ADV specimens were produced after the two other composites and only one sample was immersed at each temperature for 120 days, Figure 3c.

The diffusion kinetics of the three composite materials can also be fitted to a Fickian expression, at least initially. A stable weight gain is reached after about four months at $60^{\circ} \mathrm{C}$ but then a sharp increase in weight gain is noted. One explanation for this might be a drop in the glass transition temperature $(\mathrm{Tg})$ of the resin (initially around $80^{\circ} \mathrm{C}$ ) which falls below the test temperature, so the resin enters a rubbery state and can absorb more water. Jones [29] indicates that the $\mathrm{Tg}$ of cured epoxy resins drop on average by $20 \mathrm{~K}$ for $1 \%$ absorbed water. However, if this was the case the weight increase would also be observed in the pure resin and this was not the case, even after 2 years at $60^{\circ} \mathrm{C}$. More work is needed to understand this phenomenon, which appears to be linked to the long term behaviour of the polyester stitching thread (dry $\operatorname{Tg} 65^{\circ} \mathrm{C}$ ) which holds the fibres together.

An optimization routine based on the least squares method has been used to define the diffusion coefficients $\mathrm{D}$ (Table 3 ) but only for the first part of the curves up to this change in weight gain. Increasing the immersion temperature from $4^{\circ} \mathrm{C}$ to $60^{\circ} \mathrm{C}$ results in an acceleration of water entry by a factor of at least 80 for the resin and composite materials. Changing the type of glass fibre does not affect the diffusion behaviour significantly, similar saturated weight gains and diffusion coefficients are noted. 


\subsection{Quasi-static properties}

Quasi-static flexural tests have been performed in order to determine the failure stresses in four-point bending of the three composite materials. The following mean flexural failure strengths with their standard deviations were obtained: E-glass 1138 (64) MPa, ADV 1330 (47) MPa and HP 1314 (86) MPa. For the E-glass samples flexural tests were also performed on $25 \mathrm{~mm}$ wide parallel sided specimens, as noted previously, and the mean strength was around $800 \mathrm{MPa}$. This is significantly lower than expected due to the local indentation failure mechanism, and similar to values from tensile tests on dogbone specimens. Both of the improved glass fibres give higher strengths than the reference E-glass composites. Flexural failure occurs in compression, on the upper face of the specimen in all cases.

\subsection{Effects of wet ageing on the mechanical properties of the materials}

In order to develop a better understanding of sea water ageing and its consequences on the composite materials studied, quasi-static tests were performed at different stages of ageing. Two series of tests have been performed, first on the unreinforced resin then on the composites. Specimens were kept in natural sea water at $20^{\circ} \mathrm{C}$ until testing, at least three composite specimens were tested for each condition. The duration of ageing periods in natural sea water at $60^{\circ} \mathrm{C}$ are shown in Table 3 .

\subsubsection{Tests on pure resin}

Tensile tests have been performed on wet specimens (within 30 minutes of removal from water). Stresses, strains and Young's moduli (defined over the range $0-2 \mathrm{kN}$ ) were determined, and their variations with respect to the experimental results obtained in the initial state are given in Table 4. Failures always occurred in the central parallel section of the specimens. Figure 4 shows how resin failure stress evolves with ageing time and weight gain. These curves are presented as a function of the root square of the ratio days of immersion divided by the thickness to account for the variability of the geometric parameters of the specimens. Both the failure stress and the Young's moduli are reduced by prolonged immersion in natural sea water at $60^{\circ} \mathrm{C}$, but failure strain is less affected.

\subsubsection{Tests on composites}

Flexural tests were performed on wet, aged, infused E-glass, ADV and HP specimens, the experimental values of failure stresses in four-point bending are presented on Figure 5 . Sea water ageing has a large influence on the flexural failure stress, especially for the composite reinforced with E-glass. This test is particularly sensitive to ageing as the regions of maximum stress are at the surfaces which are in direct contact with water. There is a correlation between the evolution of the specimen weight gain and the variation of the failure stress. The failure stress decreases by $5 \%$ during the first week of sea water ageing for the infused E-glass composite and by almost $40 \%$ after 5040 hours. The measured failure stress for the infused ADV composite decreases by $30 \%$ after 504 hours of immersion and by $50 \%$ after 2604 hours. For the infused HP composite, the decrease in the failure stress varies between $30 \%$ after 2688 hours of immersion and $40 \%$ after 5040 hours. For the $\mathrm{E}$ and HP glass materials a series of specimens aged for 3024 hours was fully dried (to constant weight) before testing. In this case the loss in strength is partly reversible, the drops in failure strength were reduced to $30 \%$ and $16 \%$ respectively.

Three specimens of infused E-glass and HP materials were left for additional long term ageing in sea water (11 760 hours, 16 months), and results revealed that the E-glass 
composites continued to lose strength $(-56 \%)$ while the HP reinforced material strength remained stable at $-40 \%$. This indicates the importance of long term testing to validate material choices, after 5040 hours the losses were similar for the both materials. In order to complete these results, examples of the flexural stress-displacement plots for the different ageing stages are shown in Figure 6. There is no significant change in flexural stiffness after ageing, axial modulus values are around $46 \mathrm{GPa}$ for E-glass and up to $56 \mathrm{GPa}$ for composites based on the stiffer HP fibres.

Given the large changes in flexural strength but quite small matrix resin changes (albeit in tension) one might assume that it is the fibre/matrix interface region which is affected by water. An additional series of tests, to determine interlaminar shear stress (ILSS) values, was performed on E-glass specimens aged under the same conditions but allowed to dry in air for over 6 months before testing. The values obtained represent therefore the irreversible changes introduced by aging, not reversible changes such as resin plasticisation. Figure 7 presents the results, for at least 4 specimens per condition. Up to 2000 hours there is a small drop in ILSS but the values remain quite high after all aging times. A more detailed study of interface properties in the wet state would be required to clarify the mechanisms contributing to the large drop in flexural strength after ageing shown in Figure 5 but the reduction in resin properties on the surface in compression exposed to water is probably the first step.

\subsection{Effects of wet ageing on failure mode during flexural tests}

Four-point bending tests are complex, involving tensile, compressive and shear stresses. This is an advantage in a preliminary study as it enables the critical behaviour to be determined in one test, but it also makes interpretation more difficult than for separate tension or compression tests. Table 6 shows failed infused E-glass specimens tested in bending after different ageing periods. In the initial state, the specimens all failed in compression (C). During the natural sea water ageing process, the failure mode of the specimen under flexural loading changed from compression (C) to tension $(T)$. This change, which may be due to a stress corrosion mechanism in the E-glass [30-32], occurred between 168 hours and 1344 hours of immersion. After 5040 hours the tensile failure is very localized in the specimen centre. Similar changes in failure mode were noted for the composites with the other fibre compositions, initially compression but changing to tension after immersion. Examples of scanning electron microscope photos of the failure regions of two specimens are shown in Figure 8. Close inspection of the tensile failure region revealed some fibre damage, Figure 8c, which may indicate stress corrosion. In order to understand the change in failure mode observed during the flexural tests, a simplified numerical model taking into account the water distribution and its effect on mechanical properties has been created using Comsol Multiphysics software. The specimen is modeled as an orthotropic material using tetrahedral Lagrange elements. It is loaded in flexure and at the same time a Fickian water diffusion model is applied using the diffusion coefficient in Table 3.

As presented previously, the mechanical parameters which are most affected by the wet ageing are the failure stresses (in tension and compression). Their measured evolutions from tests on aged dogbone specimens tested in tension and compression have been described to a first approximation as linear functions of the ratio of water concentration to the maximum concentration in the specimen, Figure 9. It should be noted that the absolute strength values measured on these specimens are lower than those obtained in flexure, but it is assumed that their evolution with aging is similar. The simulated specimen is loaded in bending and considered to be loaded while completely immersed in natural sea water at $60^{\circ} \mathrm{C}$. This is not exactly the real situation, as specimens were first aged then loaded, but as the modulus (and hence the stress state) does not vary with water ingress (weak coupling) a single model can be used to combine the two effects. This model allows us to determine the zones where the 
computed longitudinal stress is superior to the failure stresses (either in tension or in compression), which decrease locally and are re-calculated at all points as the water diffuses in the specimen, Figure 10. During the early stages of ageing, the zone initially damaged in bending is on the upper face of the specimen (in red) which is loaded in compression. At longer immersion times as the water concentration in the specimen increases, the damaged zone on the upper face expands and progresses in the thickness of the specimen. After around 500 hours, a large damaged zone appears on the lower face of the specimen loaded in tension. The numerical model shows that the damaged zones become almost symmetrical around 500 hours which is consistent with the experimental observations. This type of coupled model can be useful in designing test programmes to qualify composites for ocean energy applications, as it indicates how the critical loading cases for long term immersion depend on geometry. This is important as, for example, the use of compression tests alone to evaluate aging behaviour in a material qualification programme will not necessarily provide conservative design data.

\section{Conclusion}

Ocean energy applications are a new area for composites materials and the work described here is a first step toward developing a methodology to design for durability of immersed structures such as tidal turbines. The materials tested are those currently used for wind turbine blades, known to show good fatigue behaviour.

Weight gains during immersion in natural sea water of both unreinforced resin and infused composites can be described by a Fickian diffusion model. Fibre type does not affect water absorption significantly. A large reduction (from $40 \%$ to $56 \%$ ) in the quasi-static strengths of the composite materials due to the sea water absorption has been revealed by performing static tests after different sea water ageing periods. The residual failure stresses in bending decrease when the water absorption increases, especially for composite materials reinforced with E-glass fibre, while axial modulus remains unchanged. HP glass fibres confer improved long term property retention compared to standard E-glass fibres. Both matrix and fibre/matrix interface changes contribute to the loss in strength, but tests performed on specimens dried after ageing have shown that these changes are partially reversible.

The mechanical properties of both the pure resin material and the infused composites are linked to the water absorption, and a coupled approach must be used to design ocean energy conversion structures if costly failures are to be avoided. Knowledge of the fatigue behaviour of these materials in sea water is also essential, and this aspect has been examined in a separate study.

\section{Acknowledgements}

The authors are grateful to the members of this project for advice and support, in particular to Claude Renaud, Paul Lucas and Georg Adolphs (OCV), Luc Peters, Philippe Nellissen (3B), Rolf Nickel and Christoph Kensche (Momentive), Dominique Perreux (MaHyTec), and Dominique Choqueuse, Nicolas Lacotte, Albert Deuff and Benoit Bigourdan (IFREMER Brest). 


\section{References}

[1] IFREMER. Synthèse de l'étude prospective sur les énergies renouvelables marines à I'horizon 2030, March 2008.

[2] IEA/ICOE annual report, 2007.

[3] European Commission, Ocean Energy Conversion in Europe, 2006.

[4] Frau J, Tidal energy: promising projects : La Rance, a successful industrial scale experiment. Energy Conversion, IEEE Transactions. 1993, 8(3), 552-8.

[5] Mueller $\mathrm{M}$, Wallace R, Enabling science and technology for marine renewable energy. Energy Policy. 2008, 36(12), 4376-82.

[6] Davies P, Lemoine L, editors, Nautical applications of composite materials. Proc 3rd IFREMER Conference, 1992, Paris, France.

[7] Shenoi R, Wellicome J. Composites in marine structures. Cambridge University Press. 2008.

[8] Davies P, Choqueuse D. Ageing of composites in marine vessels. In: Martin R, ed. Ageing of composites, Woodhead Publishers 2008.

[9] Smith CS Design of marine structures in composite materials. London, Elsevier Science Publishers 1990.

[10] Mouritz A, Gellert E, Burchill P, Challis K. Review of advanced composite structures for naval ship and submarines. Composite Structures. July 2001, 53(1), 21-42.

[11] Lemière $Y$. The evolution of composite materials in submarine structures, in ref. [6]

[12] Gibson A. The cost effective use of fibre reinforced composite offshore: HSE report 39, 2003.

[13] Baldwin DD, Newhouse N, Lo K. Composite production riser design. Proc. 29th annual Offshore Technology Conference, 1997, Houston, USA.

[14] Springer GS, ed. Environmental Effects on Composite Materials, Technomic 1981.

[15] Davies P, Baizeau R, Choqueuse D, Salmon L, Nagot F. Aging and long term behavior of composite tubes. Recent developments in durability analysis of composite systems, DURACOSYS, 1999, Balkema Press.

[16] Richard F, Perreux D. The safety-factor calibration of laminates for long-term applications: behavior model and reliability method. Comp Sci \& Tech. 2001, 61, 2087-94.

[17] Gellert E, Turkey D. Seawater immersion ageing of glass-fibre reinforced polymer laminates for marine applications. Composites Part A, Nov. 1999, 30(11), 1259-65.

[18] Davies, P, Mazeas, F, Casari, P. Sea water aging of glass reinforced composites : Shear behaviour and damage modelling. Jnl of Composite Materials. 2001, 35(15),1343-72.

[19] Maurin R, Perrot Y, Bourmaud A, Davies P, Baley C. Seawater ageing of low styrene emission resins for marine composite: Mechanical behaviour and nano-indentation studies. Composites Part A, August 2009, 40(8), 1024-32.

[20] Weitsman Y. Moisture in composites: sorption and desorption. In: Reinfsnider KL, ed. Fatigue of composite materials. Amsterdam: Elsevier 1991, 385-429.

[21] Ageing of composites. R Martin ed: Woodhead Publishers 2008.

[22] Marsh G. Tidal turbines harness the power of the sea. Reinf. Plastics, 2004, 48, 44-7.

[23] Fraenkel PL. Tidal Current Energy Technologies, Ibis. 2006, 145-51.

[24] Fraenkel PL. Development and testing of Marine Current Turbine's SeaGen 1.2 MW tidal stream turbine. 3rd International Conference on Ocean Energy; October 2010; Bilbao.

[25] OpenHydro press release. http://www.openhydro.com/news/171210.html Dec. 2010

[26] Antheaume S, Maître T, Achard J. Hydraulic Darrieus turbines efficiency for free fluid flow conditions versus power farm conditions, Renewable Energy, October 2008, 33, 218698

[27] Zanette, J, Imbault, D, Tourabi, A. A design methodology for cross flow water turbines, Renewable Energy. 2010, 35(5), 997-1009.

[28] Marsh G. Wave and tidal power - an emerging new market for composites. Reinforced Plastics. June-July 2009, 53(5), 20-24. 
[29] Jones F. Durability of reinforced plastics in liquid environments. In: Pritchard G, ed. Reinforced plastics durability, Woodhead Publishing, 1999.

[30] Charles R. Static fatigue of glass I. J Applied Physics, 1958, 29(11), 1549-60.

[31] Price J, Hull D. Propagation of stress corrosion cracks in aligned glass fibre composite materials. J Materials Sci. 1983, 18, 2798-810.

[32] Pauchard V, Grosjean F, Campion-Boulharts $H$, Chateauminois A. Application of a stress-corrosion-cracking model to an analysis of the durability of glass/epoxy composites in wet environments. Comp Science and Technology. 2002, 62(4), 493-8.

Tables

Table 1. Fibre properties (suppliers' data measured according to ASTM D2343)

\begin{tabular}{|c|c|c|c|}
\hline Fibre & Reference & Tensile strength [MPa] & Tensile modulus [GPa] \\
\hline E-glass & E & $2000-2500$ & $74-80$ \\
\hline Advantex ${ }^{\circ}$ & ADV & $2200-2600$ & $81-83$ \\
\hline HiPer-tex ${ }^{\text {TM }}$ & HP & $2800-2900$ & $89-91$ \\
\hline
\end{tabular}

Table 2. Quality control results

\begin{tabular}{|l|c|c|c|}
\hline & $\operatorname{Tg}\left[{ }^{\circ} \mathrm{C}\right]$ & $\mathrm{V}_{\mathrm{f}}$ (s.d.) [\%] & ILSS (s.d.) [MPa] \\
\hline E-glass/Epoxy & $77 \pm 2$ & $55.1(3.1)$ & $51.0(2.4)$ \\
\hline ADV/Epoxy & $84 \pm 2$ & $60.2(0.4)$ & $52.1(1.4)$ \\
\hline HP/Epoxy & $82 \pm 2$ & $57.5(2.1)$ & $50.2(2.8)$ \\
\hline
\end{tabular}


Table 3. Summary of the natural sea water ageing data for the pure resin and composite materials

\begin{tabular}{|c|c|c|c|c|c|}
\hline \multirow{2}{*}{ Material } & \multirow{2}{*}{$\begin{array}{c}\text { Mass at } \\
\text { saturation } \\
{[\%]}\end{array}$} & \multicolumn{4}{|c|}{ Diffusion coefficient D, (s.d.) $\left[10^{-14} \mathrm{~m}^{2} / \mathrm{s}\right]$} \\
\cline { 4 - 6 } & 2.5 & $2.58(0.06)$ & $6.66(0.20)$ & $31.83(0.37)$ & $176.5(7)$ \\
\hline Resin & $4{ }^{\circ} \mathrm{C}$ & $20^{\circ} \mathrm{C}$ & $40^{\circ} \mathrm{C}$ & $60^{\circ} \mathrm{C}$ \\
\hline E-glass composite & 0.75 & $1.16(0.08)$ & $3.59(0.13)$ & $17.33(7.81)$ & 119.33 \\
& & & & & $(6.99)$ \\
\hline HP composite & 0.70 & $0.72(0.08)$ & $2.82(1.07)$ & $16.32(0.79)$ & 105.73 \\
& & & & & $(7.74)$ \\
\hline
\end{tabular}

Table 4. Summary of the ageing periods in hours at $60^{\circ} \mathrm{C}$, defined for the pure resin and infused composite specimens. ( ${ }^{*}$ followed by drying to constant weight).

\begin{tabular}{|c|c|c|c|}
\hline \multirow{2}{*}{$\begin{array}{l}\text { Pure resin } \\
\text { specimens }\end{array}$} & \multicolumn{3}{|c|}{ Composite specimens } \\
\hline & E-glass & ADV & $\mathrm{HP}$ \\
\hline 31 & 168 & 504 & 2688 \\
\hline 96 & 672 & 1008 & 3024 * \\
\hline 177 & 1344 & 2016 & 5040 \\
\hline 361 & 2016 & 2604 & 11760 \\
\hline 529 & 2688 & & \\
\hline 1275 & 3024 * & & \\
\hline 2140 & 5040 & & \\
\hline & 11760 & & \\
\hline
\end{tabular}


Table 5. Summary of the experimental data of failure stresses, strains and Young's moduli obtained in tensile tests on aged pure resin specimens and their variations with respect to the initial state

\begin{tabular}{|c|c|c|c|c|c|c|}
\hline Condition & \multicolumn{2}{|c|}{$\begin{array}{c}\sigma_{\text {fail }} \text { (min-max range) } \\
{[\mathrm{MPa}]}\end{array}$} & $\begin{array}{c}\varepsilon_{\text {fail }} \text { (min-max range) } \\
{[\%]}\end{array}$ & \multicolumn{2}{c|}{$\begin{array}{c}\text { E (min-max range) } \\
{[\mathrm{GPa}]}\end{array}$} \\
\hline Initial state & $\mathbf{6 8 . 4 ( \mathbf { 1 . 6 } )}$ & & $\mathbf{4 . 9 4 ( \mathbf { 0 . 1 } )}$ & & $\mathbf{2 . 8 ( 0 . 2 )}$ & \\
\hline $31 \mathrm{~h}$ & $66.7(1.8)$ & $-3 \%$ & $5.33(0.08)$ & $+8 \%$ & $2.5(0.2)$ & $-10 \%$ \\
\hline $96 \mathrm{~h}$ & $64.9(3.8)$ & $-5 \%$ & $4.80(1.24)$ & $-3 \%$ & $2.4(0.2)$ & $-15 \%$ \\
\hline $177 \mathrm{~h}$ & $63.4(1.0)$ & $-7 \%$ & $4.73(0.90)$ & $-4 \%$ & $2.7(0.02)$ & $-4 \%$ \\
\hline $361 \mathrm{~h}$ & $54.9(13.4)$ & $-20 \%$ & $3.55(1.90)$ & $-28 \%$ & $2.2(0.4)$ & $-23 \%$ \\
\hline $529 \mathrm{~h}$ & $55.3(9.6)$ & $-19 \%$ & $4.83(3.80)$ & $-4 \%$ & $2.0(0.1)$ & $-31 \%$ \\
\hline $1275 \mathrm{~h}$ & $56.2(2.8)$ & $-18 \%$ & & & & \\
\hline $2140 \mathrm{~h}$ & $54.2(2.4)$ & $-21 \%$ & $4.94(2.80)$ & $0 \%$ & $1.8(0.2)$ & $-34 \%$ \\
\hline
\end{tabular}

Table 6. Summary of the typical failure modes for flexural tests on infused E-glass specimens after different ageing periods in sea water at $60^{\circ} \mathrm{C}$. C: Compression, T: Tension.

\begin{tabular}{|c|c|c|c|c|}
\hline \multirow{2}{*}{\multicolumn{2}{|c|}{$\begin{array}{c}\text { Failure mode } \\
\text { Initial state }\end{array}$}} & Face in compression & Face in tension & \multirow{2}{*}{$\begin{array}{c}\begin{array}{c}\text { Failure } \\
\text { mode }\end{array} \\
\mathrm{C}\end{array}$} \\
\hline & & $43-11$ & CS & \\
\hline \multirow{6}{*}{$\begin{array}{l}\text { Failure } \\
\text { mode } \\
\text { after } \\
\text { natural } \\
\text { sea water } \\
\text { ageing } \\
\left(60^{\circ} \mathrm{C}\right)\end{array}$} & 168 hours & $\operatorname{IE2}-3$ & 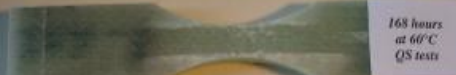 & $\mathrm{C}$ \\
\hline & 672 hours & IE2. $6 \cdots$ & 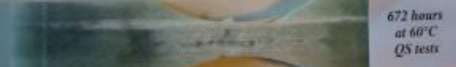 & $\mathrm{C}+\mathrm{T}$ \\
\hline & 1344 hours & IE2.9 & 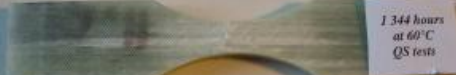 & $\mathrm{T}$ \\
\hline & 2016 hours & IE. 1 & 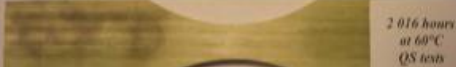 & $\mathrm{T}$ \\
\hline & 2688 hours & $I E \Lambda .9$ & 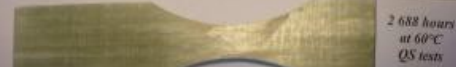 & $\mathrm{T}$ \\
\hline & 5040 hours & IEA.13 & 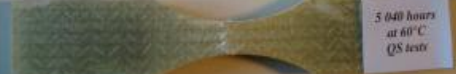 & $\mathrm{T}$ \\
\hline
\end{tabular}




\section{Figures}

Figure 1. Test specimens (dimensions in $\mathrm{mm}$ )

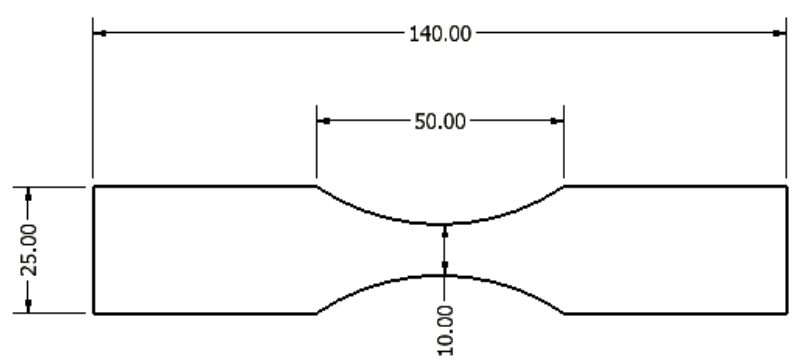

Figure 2. Stress-strain plots from flexure, tension and compression tests on E-glass dog-bone specimens

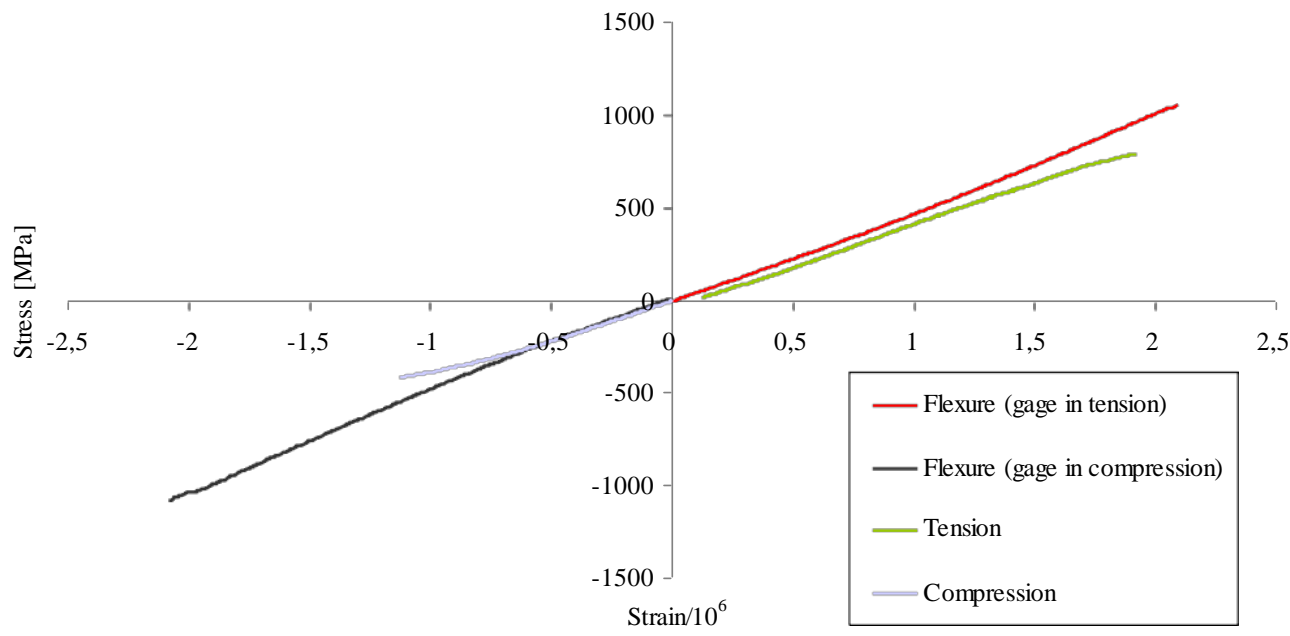


Figure 3. Plots of experimental weight gain data (points) and optimization results (lines) for infused E-glass (a) and HP (b) and ADV (c) specimens

(a)

$$
\text { E-glass }
$$

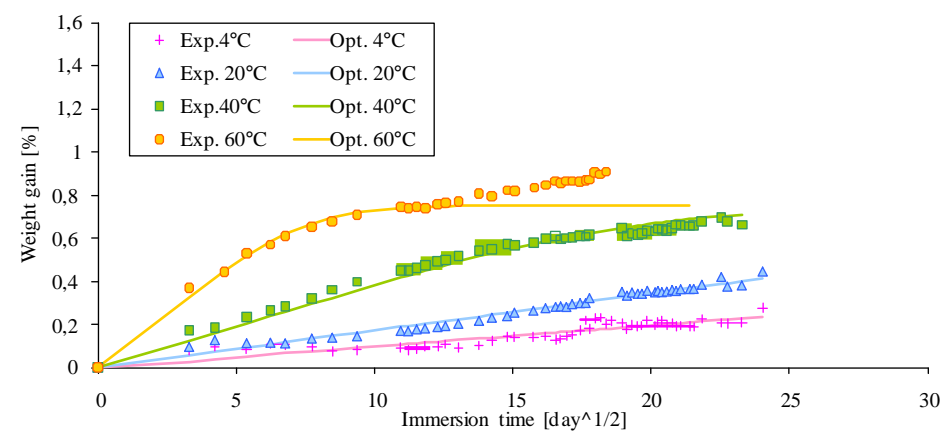

(b)

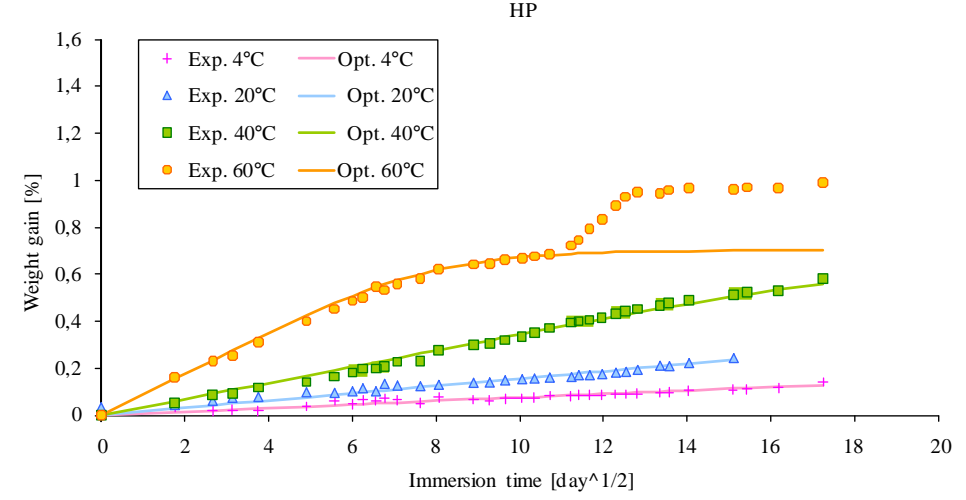

(c)

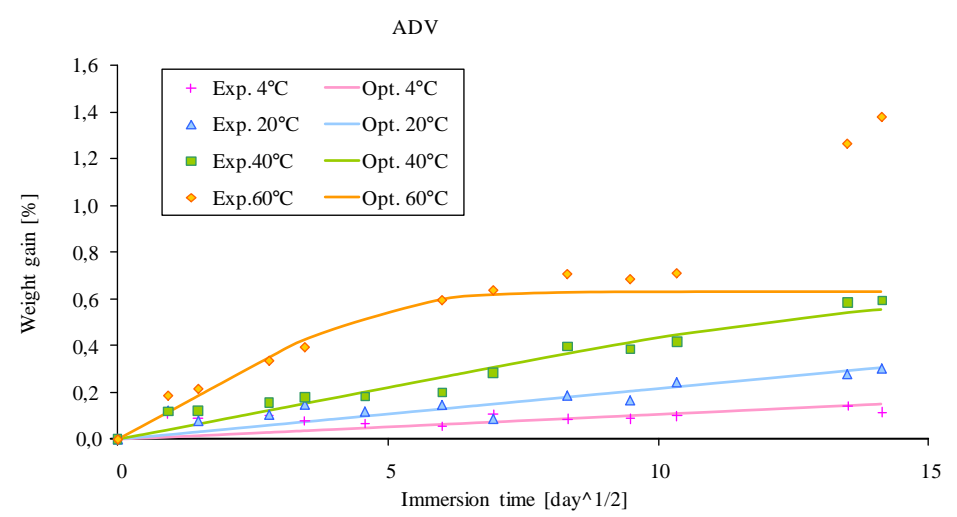


Figure 4. Evolutions of the tensile failure stresses for pure resin specimens as a function of the immersion time and the weight gain calculated for the dog-bone specimen

Pure resin

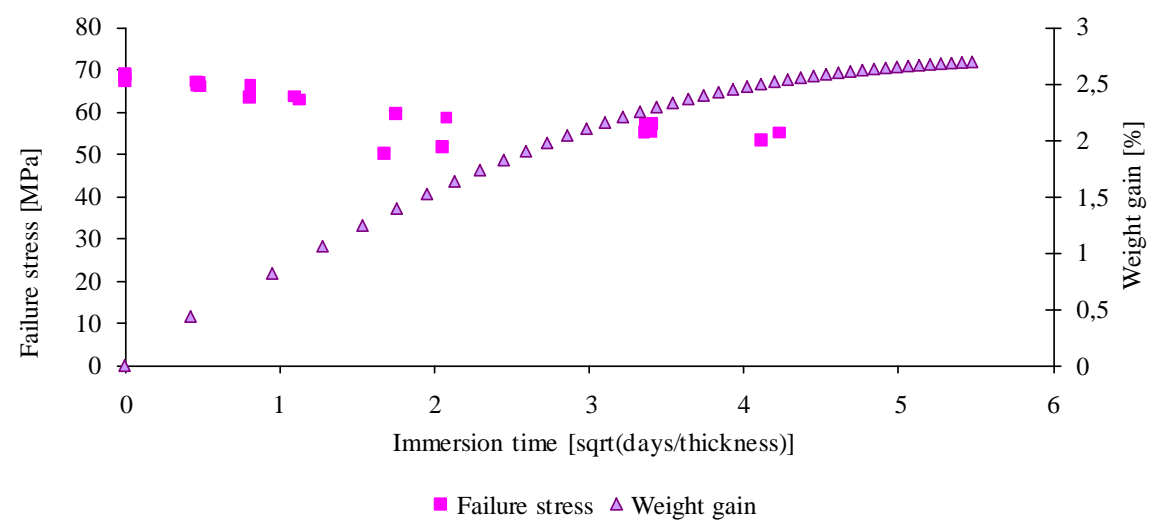

Figure 5. Evolution of the flexural failure stresses for infused composite specimens as a function of the immersion time and the weight gain

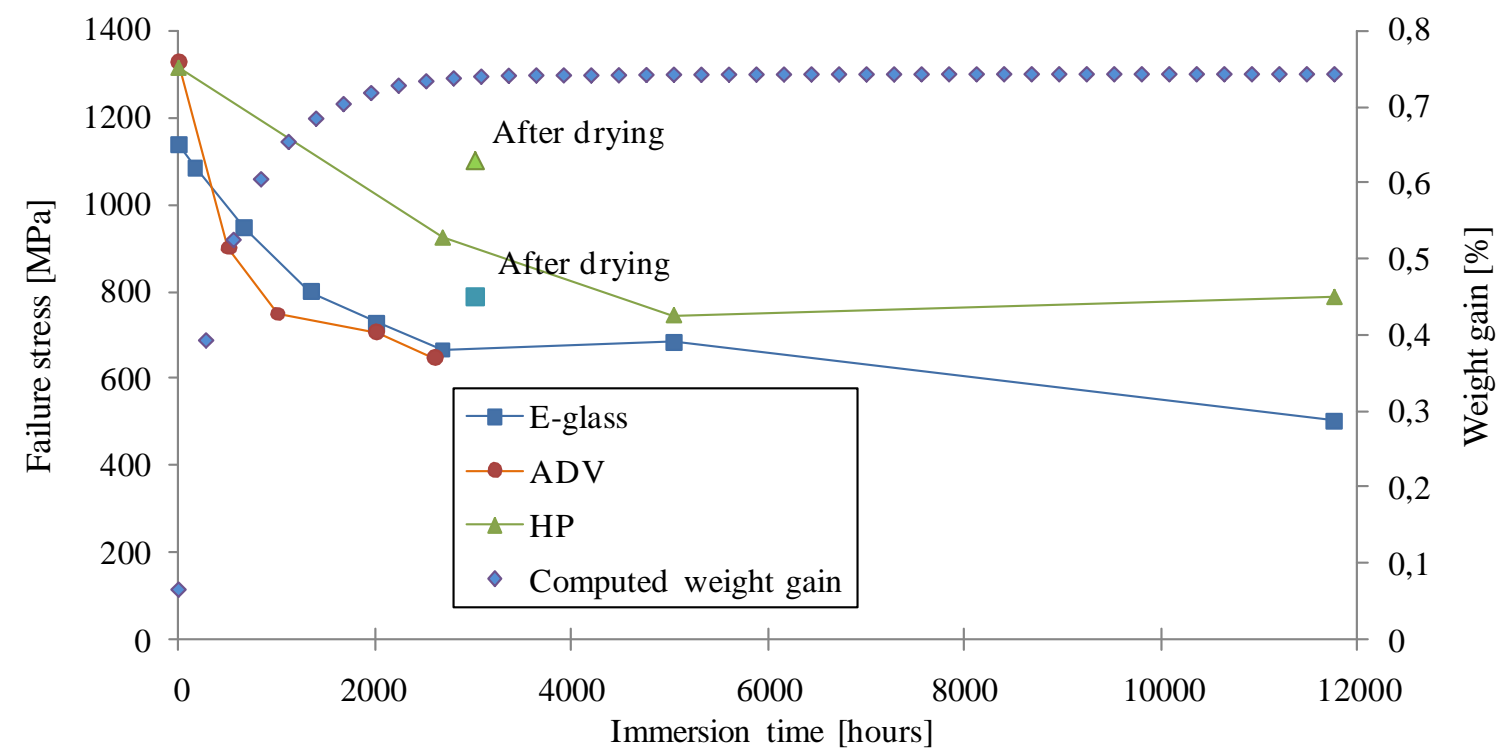


Figure 6. Evolution of the flexural stress-displacement plots for the different ageing stages for infused E-glass composite

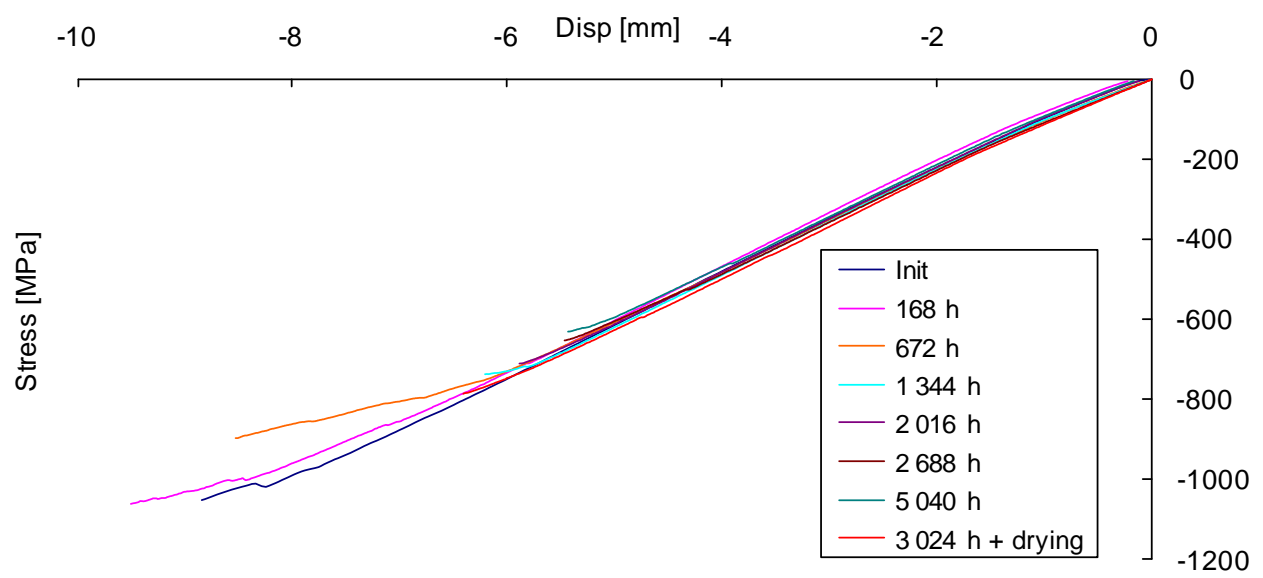

Figure 7. Evolution of the ILSS data for dried infused E-glass specimens as a function of the immersion time

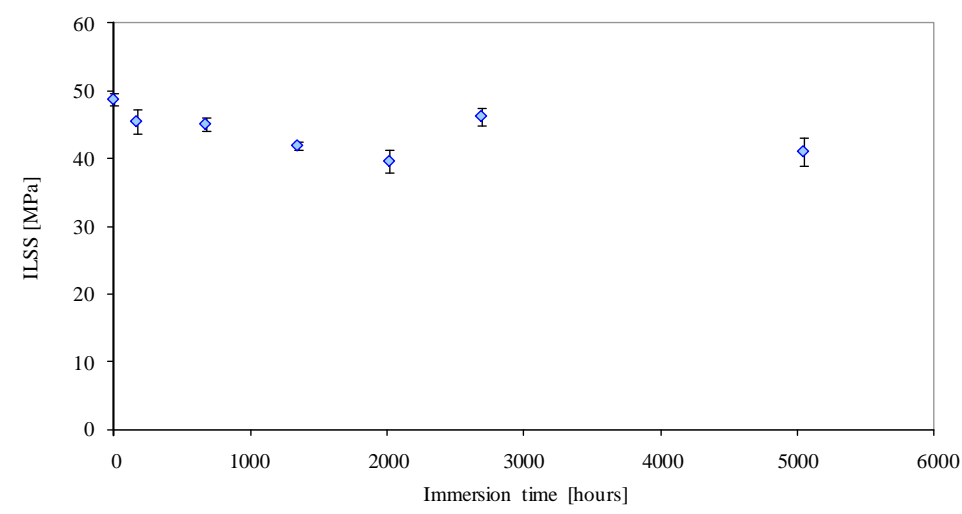


Figure 8. Scanning electron microscope images of E-glass reinforced composites : a) $168 \mathrm{~h}$ at $60^{\circ} \mathrm{C}$, compression face, b) $2016 \mathrm{~h}$ at $60^{\circ} \mathrm{C}$, tension face, c) detail of fibre damage in photo $8 \mathrm{~b}$. Specimen axis horizontal. (NB The surface pattern is due to peel ply removal).

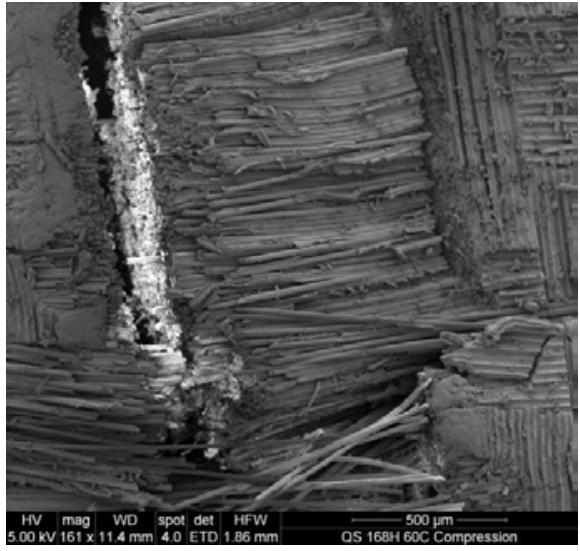

Compression $\rightarrow \leftarrow$

(a)

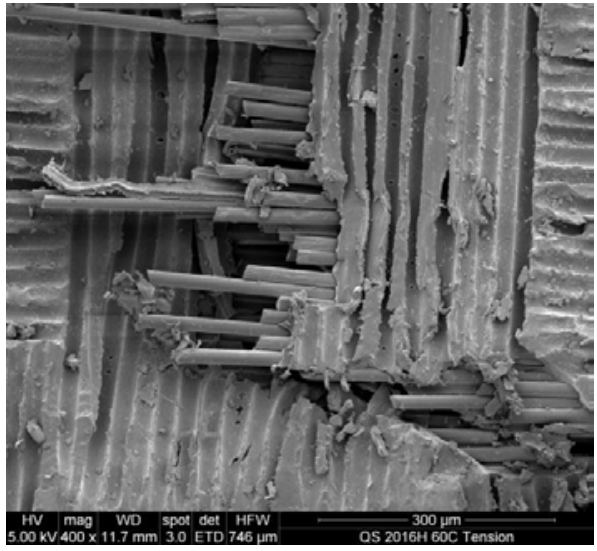

Tension $\leftarrow \rightarrow$

(b)

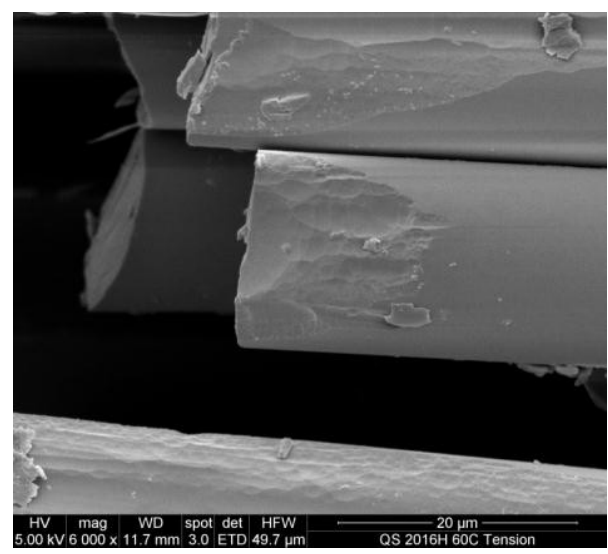

(c) 
Figure 9. Tensile and compression failure strengths versus calculated water contents in dog-bone specimens, simple linear property evolution used in numerical model of flexure specimen

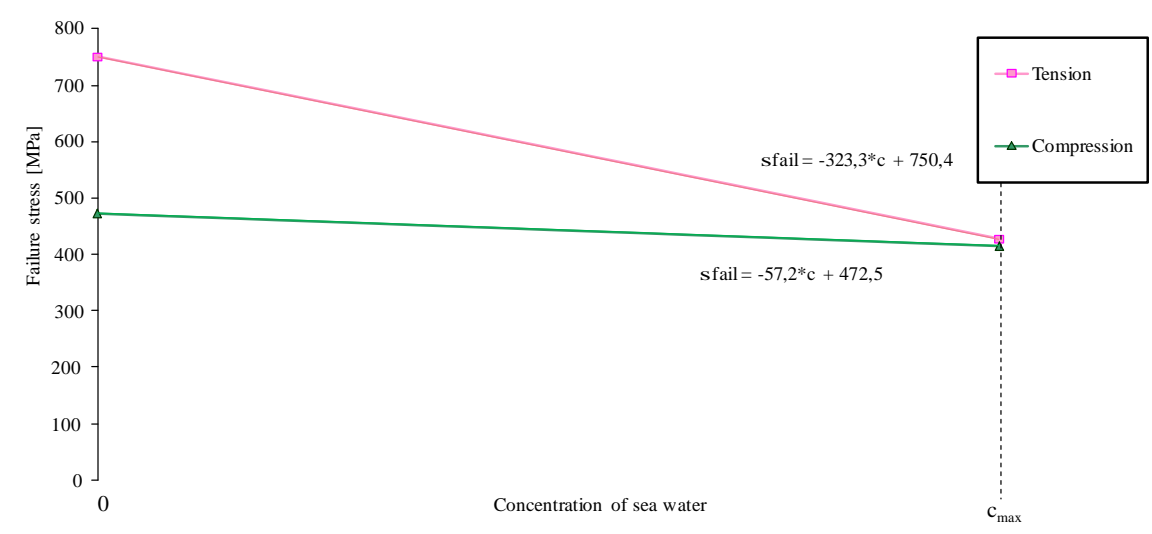

Figure 10. Evolution of the calculated damage zones (in red) as a function of the immersion time.

Initial
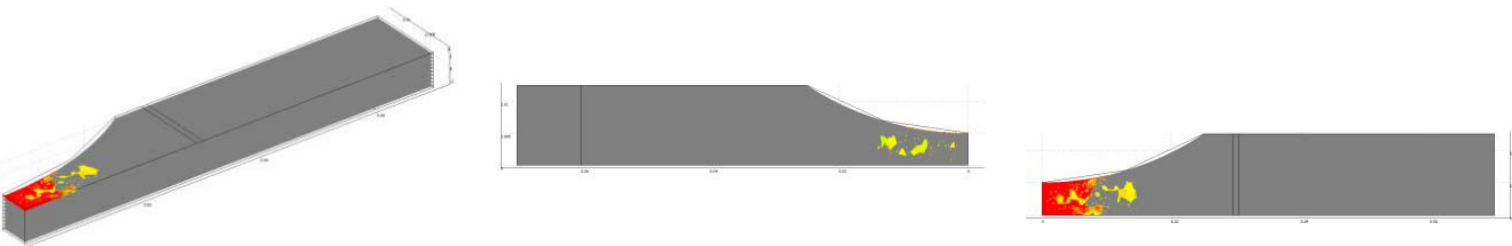

100 hours
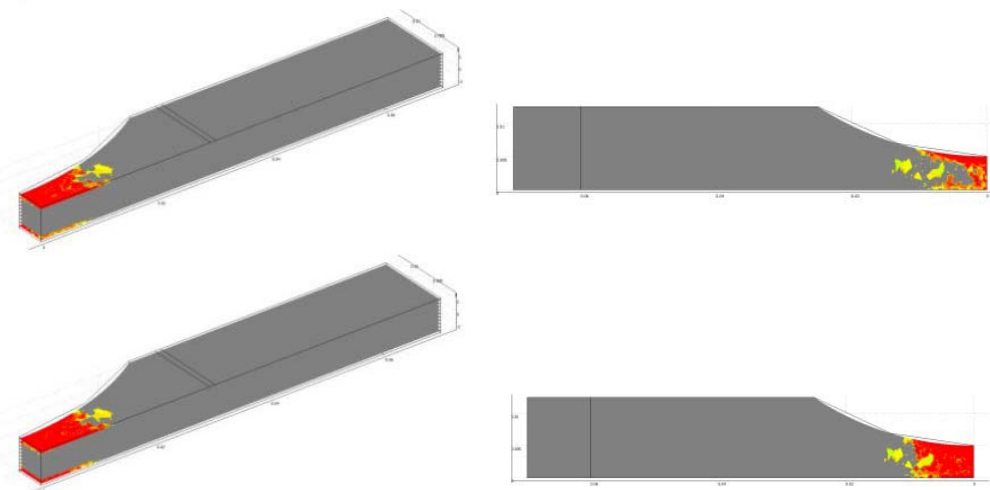

500 hours

1500 hours
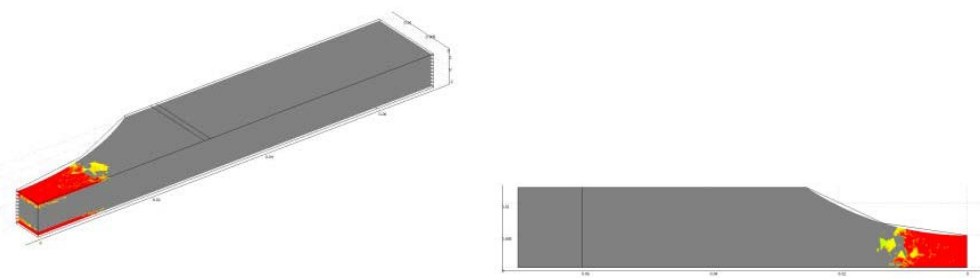

Face in tension

Face in compression 